\title{
Modifications of physical and chemical parameters of the air in the process of food preparation in household kitchens in the Republic of Moldova
}

DOI: $\underline{\text { http://doi.org/10.26758/7.1.2 }}$

Cătălina Croitoru (1, 3), Elena Ciobanu (1), Angela Cazacu-Stratu (2)

(1) State University of Medicine and Pharmacy "Nicolae Testemiţanu", Chisinau, Republic of Moldova, General Hygiene Department

(2) State University of Medicine and Pharmacy "Nicolae Testemiţanu", Chisinau, Republic of Moldova, Hygiene Department

(3) National Centre of Public Health, Chisinau, Republic of Moldova, Scientific laboratory of Occupational Helth

Address correspondence to: Cătălina Croitoru, Ph.: +37368716501; e-mail: catalina.croitoru@usmf.md

\begin{abstract}
Objectives. The aim of the study was the evaluation of the air quality in the process of food preparation in rural households of the Republic of Moldova.

Material and methods. The study was conducted in three areas of the Republic of Moldova (northern, central and southern areas). We evaluated the temperature, the relative humidity of the air, as well as the carbon dioxide and the carbon monoxide in the air. The measurements were carried out during summertime, with Air Quality Monitor 500 in 4 stages: before the cooking process, one hour after the beginning of the cooking process, at the end of the cooking process and one hour after the end of the cooking process.

Results. The air temperature and the relative humidity rose the most in the process of food preparation in the room designed for living. In $3 / 4$ of the households, the concentration of the carbon dioxide in the room designed for living surpassed the limit of the norms maximum to $0.3 \mathrm{mg} / \mathrm{l}$. The concentration of carbon monoxide was detected in few cases, especially during food preparation in rooms designed for living and summer kitchens when the fuel sources were biomass and cereal crops residues.

Conclusions. Air quality worsens towards the end of the cooking process and in most cases it is maintained over an hour after the end of the preparation process, representing a source of indoor pollution to the whole family.
\end{abstract}

Keywords: air, indoor pollution, chemical parameters, food preparation.

\section{Introduction}

Perception, however subtle, about perceived indoor air quality, can be the triggering event of an emerging problem. Such perceptions are characterized as stuffy, bad, and dry air, unpleasant odor, dust, or dirt, for example (Schneider, 2008; Saha, et al., 2015). Indoor air pollution remains a large global health threat. One half of the world population, and up to $95 \%$ of the population in poor countries, continue to rely on solid fuels, including biomass fuels (wood, dung, agricultural residues) 
and coal, to meet their energy needs (Bruce, et al., 2006; Saha, et al., 2015; World Health Organization, 2015).

Cooking and heating with solid fuels on open fires or on traditional stoves generates high levels of health-damaging pollutants, such as particulates and carbon monoxide. As women are primarily responsible for cooking and as children often spend time with their mothers while these are engaged in cooking activities, women and young children are primarily affected. For example, the World Health Report (2002) estimates that the acute respiratory infection is one of the leading causes of child mortality in the world, accounting for up to $20 \%$ of fatalities among children under five, almost all of them in developing countries. This makes solid fuels the second most important environmental cause of disease after contaminated waterborne diseases and the fourth most important cause of overall excess mortality in developing countries after malnutrition, unsafe sex, and waterborne diseases (Bruce, et al., 2006; Dutta, et al., 2011; Banerjee, et al., 2012).

In addition to impacts on mortality, indoor air pollution may have long-lasting effects on general health and well-being: early exposure to indoor air pollution during childhood may stifle lung development, suggesting that the cost of this pollution may continue later in life. In fact, a growing literature indicates that environmental insults at early ages can have long-lasting influences on human health and productivity (Almond, 2006).

Indoor air pollution due to the indoor burning of polluting fuels has been associated with Acute Lower Respiratory Infections (ALRI) amongst children less than five years old (Barnes, 2005).

Exposure to indoor air pollution has been associated with chronic obstructive pulmonary disease, lung cancer, nasopharyngeal cancer, tuberculosis and diseases of the eye in adults, low birth weight and, of particular concern, acute lower respiratory infections (ALRI) such as pneumonia amongst children less than five (Bruce, et al., 2006; Smith, et al., 2000).

We decided to conduct this research because solid fuel sources are widely used in Moldova.

\section{Material and methods}

The study was conducted in three areas of the Republic of Moldova (northern, central and southern areas). The research has been based on the determination of some physical and chemical factors of the environment in the process of food preparation. With the help of the Air Quality Monitor 500, there have been measured the temperature and the relative humidity of the air - as physical parameters of the air - and from the chemical factors - the carbon dioxide and the carbon monoxide. The population prepares food in three different spaces (in specially equipped kitchens, in living rooms, or summer kitchens) and outdoors. Out of the 150 researched households - in 46 cases people prepared food in specially equipped kitchens, in 31 cases - directly in the room designed for living (the hobs or stoves), in 48 cases - in the summer kitchen and in 25 cases people prepared the food outdoors. During summertime, 4 measurements have been realized in each of the 150 households. The stages of data collection were the following: before the cooking process (the I stage of measurements), one hour after the cooking process beginning (the II stage of measurements), at the end of the cooking process (the III stage of measurements) and one hour after the end of food preparation (the IV stage of measurements).

In order to assess the conditions of food preparation, a questionnaire was completed using the method of direct interview. From this questionnaire, the answer to only one question was included in the present study - about the sources of fuel used by the population, in order to compare 
the corresponding concentrations of carbon dioxide for each of them. We have also included in the questionnaire the results of the measurements of air temperature and relative humidity.

The analysis of the results was performed using absolute values with subsequent calculation of indices. In order to specify the degree of significance in comparison to the average values we used the Student test for significance.

To determine the direction and power of the relationship between studied indices we calculated Bravis-Pearson's linear simple correlation coefficient (r). The level of statistical significance of the correlation was established using ANOVA test in the program Statgraphics Plus 2.1. The ANOVA test measures whether a significant factor contributes significantly to the variation of the response and determines the size of the variation that is due to a pure error. If the p-value in the ANOVA table is 0.05 to 0.001 , we can say that there is a significant statistical relationship between variables at a confidence level of 95.0 to $99.9 \%$.

\section{Results}

In order to evaluate the impact of meal preparation conditions on the human body, we have tested two physical factors of the air: temperature and relative humidity.

As far as the temperature of the air is concerned, before the cooking process, it presented values that depended on the temperature of the environmental/outdoor air. On the other hand, an hour after the beginning and at the end of the cooking process, the air temperature increased (regardless of the type of the rooms), and, in most cases, the temperature dropped one hour after finishing the cooking process.

By comparison, the air temperature has increased the most in the case of cooking in the inhabited room. The average value of the temperature one hour after starting to cook rose with $2.1^{\circ} \mathrm{C}$ $(\mathrm{p}<0.001)$, and at the end of cooking - with $4.5^{\circ} \mathrm{C}(\mathrm{p}<0.001)$. Whereas, an hour after finishing cooking, the air temperature fell with $2.8^{\circ} \mathrm{C}(\mathrm{p}<0.05)$. The temperature fell with $1.8^{\circ} \mathrm{C}(\mathrm{p}<0.001)$, even in comparison with the beginning of the cooking process. The lowest temperature value an hour after starting cooking was $20.5^{\circ} \mathrm{C}$, while the maximum value $-37.4^{\circ} \mathrm{C}$, at the end of the food preparation process, both the maximum and minimum temperatures increased $-23.8^{\circ} \mathrm{C}$ and $38.3^{\circ} \mathrm{C}$ respectively. One hour after the end of food preparation, the minimum temperature value dropped, on average, by $2.4^{\circ} \mathrm{C}$, but remained higher than the temperature at the beginning and in the middle of the cooking process. The maximum temperature decreased on average by $4.2^{\circ} \mathrm{C}$.

Furthermore, the average air temperature was higher when cooking outdoors, which was conditioned by high ambient temperature values at that time of the year. In such a setting, an hour after the start of preparing the meals, the average air temperature increased by $1.7^{\circ} \mathrm{C}$ (from $28.4^{\circ} \mathrm{C}$ to $30.1^{\circ} \mathrm{C}, \mathrm{p}<0.001$ ) and at the end by $4.4^{\circ} \mathrm{C}$ (from $28.4^{\circ} \mathrm{C}$ to $32.8^{\circ} \mathrm{C}, \mathrm{p}<0.001$ ). What is more, an hour after cooking, the air temperature decreased by $2.9^{\circ} \mathrm{C}$ (from $29.9^{\circ} \mathrm{C}$ to $28.4^{\circ} \mathrm{C}, \mathrm{p}<0.05$ ), the temperature dropped by $1.5^{\circ} \mathrm{C}(\mathrm{p}<0.01)$ in comparison with the beginning of the cooking process. In the first hour of food preparation, the temperature rose to $25.8^{\circ} \mathrm{C}$ the least and the most to $34.0^{\circ} \mathrm{C}$. At the end of the preparation of meals, the lowest temperature was $26.4{ }^{\circ} \mathrm{C}$ and the highest of $36.7^{\circ} \mathrm{C}$. However, an hour after the end of cooking, the lowest temperature was $24.1^{\circ} \mathrm{C}$ and highest $34.5^{\circ} \mathrm{C}$, therefore these values were higher than those before starting the cooking process (Table 1).

As mentioned above, during the summer, the population of Moldova cooks mainly in summer kitchens or usual kitchens (specially arranged places in the house). In view of the summer kitchens, the air temperature increased in the first hour by $1,6^{\circ} \mathrm{C}$ (from $28.9^{\circ} \mathrm{C}$ to $30.5^{\circ} \mathrm{C}, \mathrm{p}<0.001$ ) and until the end of the cooking process by $3.8^{\circ} \mathrm{C}(\mathrm{p}<0.001)$, reaching $32.7^{\circ} \mathrm{C}$. Nonetheless, one hour after the end of the cooking process the temperature decreased by $2.8^{\circ} \mathrm{C}(\mathrm{p}<0.01)$ being $29.9^{\circ} \mathrm{C}$, 
with only $1{ }^{\circ} \mathrm{C}$ increased in comparison with the one recorded at the beginning of the cooking process $(\mathrm{p}<0.01)$. The minimum temperature value, which was recorded one hour after the beginning of food preparation, was $24.7^{\circ} \mathrm{C}$, while the maximum was $34.4^{\circ} \mathrm{C}$. At the end of the food preparation, the minimum temperature was $26.2^{\circ} \mathrm{C}$, while the maximum was $38.5^{\circ} \mathrm{C}$ (Table 1).

Apart from that, the smallest rise of the temperature was registered in the kitchens, because they were specially equipped rooms that had windows ( $44 \%$ of the rooms had functional windows), some also had ventilation systems (17\% had a hood, only half of which being functional at the moment; and $11 \%$ had a ventilation duct), but in the same time, the temperature returned slower to the initial values after the cooking process, probably on account of the room, which in most cases did not have a direct way out (87\%), besides, not all the rooms had windows (28\% of the kitchens were without windows).

In settings such as specially equipped kitchens, one hour after the beginning of the food preparation process the average air temperature rose by $1.4^{\circ} \mathrm{C}$ (from $27.6^{\circ} \mathrm{C}$ to $29.0^{\circ} \mathrm{C}, \mathrm{p}<0.05$ ) and at the end by $3.2^{\circ} \mathrm{C}$ (up to $30.8^{\circ} \mathrm{C}, \mathrm{p}<0.001$ ). One hour after the end of the cooking process, the average air temperature dropped by $2.1^{\circ} \mathrm{C}(\mathrm{p}<0.001)$, and compared with the middle of the cooking process by $1.1^{\circ} \mathrm{C}(\mathrm{p}<0.001)$. Finally, at the end of the cooking process, the minimum temperature was $26.2^{\circ} \mathrm{C}$ and increased by $2.4^{\circ} \mathrm{C}$ in comparison with the initial one, being the highest increase compared to cases where food is prepared in rooms designed for living, summer kitchens and outdoors. The maximum temperature in the kitchens reached values of $38.5^{\circ} \mathrm{C}$, registering the lowest growth $\left(6.4^{\circ} \mathrm{C}\right)$ compared to cooking in other areas (Table 1$)$.

Table 1. Average, minimum and maximum air temperature values in the cooking process

\begin{tabular}{|c|c|c|c|c|c|}
\hline \multirow{2}{*}{\multicolumn{2}{|c|}{ Cooking in: }} & \multicolumn{4}{|c|}{ The air temperature $\left({ }^{\circ} \mathrm{C}\right)$} \\
\hline & & $\mathrm{T}_{1}$ & $\mathrm{~T}_{2}$ & $\mathrm{~T}_{3}$ & $\mathrm{~T}_{4}$ \\
\hline \multirow{3}{*}{$\begin{array}{l}\text { specially } \\
\text { equipped kitchens }\end{array}$} & $\mathrm{M} \pm \mathrm{m}$ & $27.6 \pm 0.26$ & $29.0 \pm 0.29^{* * *}$ & $30.8 \pm 0.39^{*}$ & $28.7 \pm 0.24^{* x}$ \\
\hline & Min & 23.8 & $24.7^{*}$ & $26.2^{*}$ & $24.5^{* *}$ \\
\hline & Max & 32.1 & $34.4^{* *}$ & $38.5^{*}$ & $33.5^{*}$ \\
\hline \multirow{3}{*}{$\begin{array}{l}\text { in the room } \\
\text { designed for } \\
\text { living }\end{array}$} & $\mathrm{M} \pm \mathrm{m}$ & $26.4 \pm 0.61$ & $28.5 \pm 0.72^{*}$ & $31.0 \pm 0.75^{*}$ & $28.2 \pm 0.60^{* * * * x}$ \\
\hline & Min & 19.5 & $20.5^{* *}$ & $23.8^{*}$ & $21.4^{*}$ \\
\hline & $\max$ & 32.4 & $37.4^{*}$ & $38.3^{*}$ & $34.1^{* *}$ \\
\hline \multirow{3}{*}{ summer kitchens } & $\mathrm{M} \pm \mathrm{m}$ & $28.9 \pm 0.26$ & $30.5 \pm 0.35^{*}$ & $32.7 \pm 0.47^{* *}$ & $29.9 \pm 0.31^{* * \mathrm{xp}}$ \\
\hline & $\min$ & 24.8 & $26.3^{* * *}$ & $28.0^{*}$ & $24.3^{*}$ \\
\hline & $\max$ & 32.6 & $35.1^{*}$ & $39.4^{*}$ & $34.1^{* *}$ \\
\hline \multirow{3}{*}{ outdoors } & $\mathrm{M} \pm \mathrm{m}$ & $28.4 \pm 0.51$ & $30.1 \pm 0.43^{*}$ & $32.8 \pm 0.46^{*}$ & $29.9 \pm 0.51^{* \operatorname{pxp}}$ \\
\hline & $\min$ & 23.6 & $25.8^{*}$ & $26.4^{*}$ & $24.1^{* *}$ \\
\hline & $\max$ & 33.4 & $34.0^{*}$ & $36.7^{*}$ & $34.5^{* * * *}$ \\
\hline
\end{tabular}

Note: $T_{1}$ - before cooking; $T_{2}$ - an hour after starting cooking; $T_{3}-$ at the end of cooking; $T_{4}-$ an hour after the end of cooking. ${ }^{*} p<0.001$. ${ }^{* *} p<0.01$. ${ }^{* * *} p<0.05$. (for $\left.T_{2}-T_{1} ; T_{3}-T_{1} ; T_{4}-T_{1}\right){ }^{\text {x }} p<0.001$. ${ }^{\text {ax }} p<0.01$. ${ }^{\text {xax }} p<005$. (for $T_{4}-T_{3}$ )

When cooking in the room designed for living, records indicated that in the first hour of food preparation, humidity increased on average by $3.2 \%$ (from $49.7 \%$ to $52.9 \%, \mathrm{p}<0.001$ ) and, at the end, by $7.6 \%$ (up to $57.3 \%$. p<0.01). An hour after finishing the cooking process, relative humidity decreased by $3.7 \%(\mathrm{p}<0.05)$ and compared to the middle of process decreased by $3.9 \%$. By contrast, when cooking outdoors the relative humidity increased in one hour by $2.3 \%(\mathrm{p}<0.01)$, and by $5.1 \%$ at the end of the cooking process $(\mathrm{p}<0.01)$. An hour after cooking, relative humidity decreased by $2.4 \%(\mathrm{p}<0.05)$ and, compared with the beginning of the process, by $2.7 \%(\mathrm{p}<0.001)$. The minimum value of relative humidity in one hour from the beginning of cooking was $41.2 \%$, 
being lower than at the beginning by $1.5 \%$. The maximum value was $60.1 \%$, being by $2.9 \%$ higher than at the beginning of the cooking process. Thus, both minimum and maximum values of humidity registered in the living room after cooking (where $21 \%$ of the population prepared the food during the summer) had shown higher fluctuations, in comparison with records from other areas of cooking, except the outdoors, where the maximum value increased over $4.3 \%$ ). At the end of meal preparation, the minimum relative humidity was $42.3 \%$, being decreased by $0.4 \%$, compared to the beginning of the cooking process, while the maximum value reached $69.9 \%$, therefore being the highest increase since the beginning of cooking compared to other spaces. One hour after the completion of cooking, the minimum value of the relative humidity decreased by $0.6 \%$ compared to the end of the processes and by $1.0 \%$ compared to its beginning. The maximum value decreased by $6.2 \%$ compared to the end of the cooking but remained higher by $6.5 \%$ compared to the beginning of the preparation of meals (Table 2).

Out of the two rooms designed for cooking during summer, the biggest changes are in the summer kitchens. There, the humidity increased by $1.6 \%$ (from $47.3 \%$ to $48.9 \%$. $\mathrm{p}<0.001$ ) in the middle and by $3.4 \%$ (from $47.3 \%$ to $50.7 \%$. $\mathrm{p}<0.05$ ) at the end of the cooking process, and one hour later it decreased by $1.8 \%(\mathrm{p}<0.01)$. The changes of the minimum and maximum values were also more common in summer kitchens compared to kitchens designed in specially equipped kitchens $(0.05<\mathrm{p}<0.001)$. In summer kitchens, the minimum value of humidity followed a lowering trend, decreasing up to $40.7 \%$ one hour after the start of preparation, while the maximum value increased up to $58.6 \%$ during the same amount of time. At the end of cooking process, the minimum relative humidity was $40.1 \%$ and decreased by $0.9 \%$ compared to the beginning of the cooking. The maximum value was $63.2 \%$ and remained higher than at the beginning by $7.0 \%$. Both absolute values and the differences in values were lower in the case of cooking in the summer kitchen compared to cooking in rooms designed for living, probably because summer kitchens are not hermetic spaces, having direct exit outdoors. One hour after the end of food preparation, the minimum and the maximum values of the relative humidity decreased compared with both the end and the initial phase of the cooking process $(0.05<\mathrm{p}<0.01)$ (Table 2$)$.

Consequently, from all four places used for food preparation, the relative humidity increased less in the case of kitchens. During the first hour, the relative humidity increased by $0.7 \%$ (from $48.5 \%$ to $49.2 \%, \mathrm{p}<0.05$ ) and by $2.5 \%$ at the end of the cooking process $(\mathrm{p}<0.001)$. One hour after cooking, the humidity decreased by $2.5 \%$ ( $\mathrm{p}<0.001)$, being $51.0 \%$, the lowest value recorded in all cooking areas. The minimum humidity value slightly increased during preparation, by $0.3 \%$ in the first hour and by $0.8 \%$ at the end of cooking. One hour after the end, the minimum value decreased by $0.6 \%$ compared to the end of the cooking process and remained by $0.2 \%$ higher than at the beginning. The maximum value was $65.0 \%$, being the highest value recorded in all cooking areas, but the dynamic of the changes was not the biggest - it decreased by $3.0 \%$ compared to the end of cooking, but remained $5.0 \%$ higher compared to the initial moment. Such a high value is explained by the fact that during summer the ventilation in the kitchen is achieved only by means of the windows, and space does not have a direct exit outside (Table 2).

Nevertheless, when cooking outdoors, the relative air humidity one hour after starting the process was equivalent to the value recorded at cooking in specially equipped kitchens (49.2\%), being slightly higher than the one recorded when cooking in summer kitchens (by $0.3 \%$ ) and lower than the one recorded in rooms designed for living $(4.1 \%) 0.01<\mathrm{p}<0.001$. The humidity increased by $2.3 \%$ ( $\mathrm{p}<0.01$ ) during the first hour of cooking (up to $49.2 \%)$, and by $5.1 \%(\mathrm{p}<0.001$ ) at the end of the process (up to $52.0 \%$ ). An hour after the completion of cooking, the relative humidity decreased by $2.4 \%(\mathrm{p}<0.001)$, but remained higher by $2.7 \%(\mathrm{p}<0.05)$ compared to initial time. The minimum relative humidity value at all stages was the lowest compared to other spaces for cooking. The 
lowest recorded value was higher by $0.8 \%$ one hour from starting meal preparation, and by $1.7 \%$ at the end of the process, while an hour after cooking it was lower by $3.0 \%$ compared with the starting point. The maximum value was $61.6 \%$ in one hour from the beginning of cooking; it reached $66.2 \%$ at the end of the preparation and decreased to $62.1 \%$ one hour after the end of the process (Table 2 ).

Table 2. Mean, minimum and maximum values of humidity in the process of cooking

\begin{tabular}{|c|c|c|c|c|c|}
\hline \multirow{2}{*}{\multicolumn{2}{|c|}{$\begin{array}{l}\text { Researched parameters } \\
\text { Cooking in: }\end{array}$}} & \multicolumn{4}{|c|}{ The relative humidity of the air $(\%)$} \\
\hline & & \multirow{2}{*}{$\begin{array}{c}\mathrm{T}_{1} \\
48.5 \pm 1.10\end{array}$} & \multirow{2}{*}{$\frac{\mathrm{T}_{2}}{49.2 \pm 0.95^{* * *}}$} & \multirow{2}{*}{$\begin{array}{c}\mathrm{T}_{3} \\
51.0 \pm 2.05^{*}\end{array}$} & \multirow{2}{*}{$\frac{\mathrm{T}_{4}}{49.1 \pm 1.14^{* x}}$} \\
\hline specially & $\mathrm{M} \pm \mathrm{m}$ & & & & \\
\hline equipped & $\min$ & 37.9 & $38.2^{* * * *}$ & $38.7^{* *}$ & $38.1^{*}$ \\
\hline kitchens & $\max$ & 60.0 & $60.0^{*}$ & $68.0^{*}$ & $65.0^{*}$ \\
\hline \multirow{3}{*}{$\begin{array}{l}\text { in the room } \\
\text { designed for } \\
\text { living }\end{array}$} & $\mathrm{M} \pm \mathrm{m}$ & $49.7 \pm 0.05$ & $52.9 \pm 1.14^{*}$ & $57.3 \pm 1.53^{* *}$ & $53.6 \pm 1.07^{* * * * x}$ \\
\hline & $\min$ & 42.7 & $41.2^{* *}$ & $42.3^{*}$ & $41.7^{* *}$ \\
\hline & $\max$ & 57.2 & $60.1^{*}$ & $69.9^{* *}$ & $63.7^{*}$ \\
\hline \multirow{3}{*}{ summer kitchens } & $\mathrm{M} \pm \mathrm{m}$ & $47.3 \pm 1.63$ & $48.9 \pm 2.11^{* *}$ & $50.7 \pm 1.16^{* * *}$ & $48.9 \pm 1.37^{* * \alpha x}$ \\
\hline & $\min$ & 41.0 & $40.7^{* *}$ & $40.1^{* *}$ & $39.7^{*}$ \\
\hline & $\max$ & 56.2 & $58.6^{*}$ & $63.2^{*}$ & $56.0^{* * * *}$ \\
\hline \multirow{3}{*}{ outdoors } & $\mathrm{M} \pm \mathrm{m}$ & $46.9 \pm 1.12$ & $49.2 \pm 0.85^{* *}$ & $52.0 \pm 1.41^{*}$ & $49.6 \pm 1.32^{* \alpha}$ \\
\hline & $\min$ & 34.0 & $34.8^{* * *}$ & $35.7^{*}$ & $32.7^{*}$ \\
\hline & $\max$ & 57.3 & $61.6^{*}$ & $66.2^{*}$ & $62.1^{*}$ \\
\hline
\end{tabular}

Note: $T_{1}$ - before cooking; $T_{2}$ - an hour after starting cooking; $T_{3}-$ at the end of cooking; $T_{4}-$ an hour after the end of cooking. " $p<0.001$. ${ }^{* *} p<0.01 .{ }^{* * *} p<0.05$. (for $\left.T_{2}-T_{1} ; T_{3}-T_{1} ; T_{4}-T_{1}\right){ }^{\mathrm{x}} p<0.001$. ${ }^{\mathrm{x}} p<0.01$. ${ }^{\mathrm{x} x \mathrm{p}} p<005$. (for $\left.T_{4}-T_{3}\right)$

There is a reason to believe that in most cases the increasing of the air humidity depends on the type of products that are prepared, as well as on the humidity of the air.

As far as the chemical factors are concerned, there have been studied the carbon dioxide and monoxide. The concentration of the carbon dioxide before cooking meals was within the normal limits, except in the inhabited rooms. In $3 / 4$ of in the room designed for living, the concentration of the carbon dioxide surpassed the normal limits up to $0.3 \%$. Calculating the average concentration of the carbon dioxide in each type of rooms, one hour after the beginning of food preparation process, we established that the limits had been surpassed in each of the cases: in kitchens - $0.18 \%$, in inhabited rooms and summer kitchens $-0.17 \%$ and in the case of preparing dishes outdoors $0.16 \%$. The maximum concentration value of carbon dioxide in kitchens was $0.5 \mathrm{mg} / \mathrm{l}$, recorded only in a room, also values of 0.28 and $0.27 \%$ were recorded in other rooms, in most of the cases, the maximum value was $0.21 \%$. In the rooms designed for living, the maximum concentration value of carbon dioxide was $0.20 \%$ and 0.21 and $0.25 \%$ in some rooms. In two summer kitchens, the maximum value of $0.27 \%$ was recorded, in some rooms -0.25 and $0.24 \%$. As for the outdoor cooking, the values are even higher: 0.30 and $0.32 \%$ in cases when wood and leftover cereals were used as fuel (Table 3).

Meanwhile, at the end of food preparation process, the average amount of carbon dioxide was greater than $0.2 \mathrm{mg} / \mathrm{l}$ in all cooking areas. The highest value was recorded in the room designed for living - $0.242 \mathrm{mg} / \mathrm{l}$ as the average of all measurements. It stands to reason that this exceeding can be justified by the fact that these spaces have a lower height and smaller volume, few rooms had ventilation hoods (only 2 of 31), two rooms had no windows, and in six rooms the windows could not be opened. The lowest value $(0.214 \mathrm{mg} / \mathrm{l})$ was registered when cooking outdoors, but also it exceeds more than twice the normal limits, especially when the fuel source was constituted of wood $(r=0.68)$, biomass $(r=0.79)$ and cereal crop residues $(r=0.73)$. 
By comparison, when cooking in summer kitchens and rooms designed for living, the concentration of carbon dioxide exceeded the normal limits even judging by the recorded minimum value $(0.13$ and $0.12 \mathrm{mg} / \mathrm{l}$, respectively). Considering the maximum value, the concentration of carbon dioxide exceeded the norm in all food preparation areas. The highest value was in the case of outdoor meals preparation $(0.4 \mathrm{mg} / \mathrm{l})$, also influenced by the type of fuel used - wood $(\mathrm{r}=0.61)$, cereal crops residue $(r=0.75)$, biomass $(r=0.66)$, while the lowest value was recorded in the kitchen areas $(0.36 \mathrm{mg} / 1)$, which are better-designed spaces.

Table 3. Mean, maximum and minimum values of concentration of carbon dioxide in the process of cooking

\begin{tabular}{|c|c|c|c|c|c|}
\hline \multirow{2}{*}{\multicolumn{2}{|c|}{$\begin{array}{l}\text { Researched parameters } \\
\text { Cooking in: }\end{array}$}} & \multicolumn{4}{|c|}{ The carbon dioxide $(\mathrm{mg} / \mathrm{l})$} \\
\hline & & $\mathrm{T}_{1}$ & $\mathrm{~T}_{2}$ & $\mathrm{~T}_{3}$ & $\mathrm{~T}_{4}$ \\
\hline \multirow{3}{*}{$\begin{array}{l}\text { specially } \\
\text { equipped } \\
\text { kitchens } \\
\end{array}$} & $\mathrm{M} \pm \mathrm{m}$ & $0.104 \pm 0.80$ & $0.177 \pm 0.87^{*}$ & $0.239 \pm 1.21^{*}$ & $0.150 \pm 0.95^{* x x}$ \\
\hline & $\min$ & 0.030 & $0.070^{* * *}$ & $0.080^{*}$ & $0.070^{*}$ \\
\hline & $\max$ & 0.300 & $0.500^{*}$ & $0.360^{* *}$ & $0.300^{* *}$ \\
\hline \multirow{3}{*}{$\begin{array}{l}\text { in the room } \\
\text { designed for } \\
\text { living }\end{array}$} & $\mathrm{M} \pm \mathrm{m}$ & $0.105 \pm 0.61$ & $0.166 \pm 0.83^{*}$ & $0.242 \pm 1.20^{*}$ & $0.149 \pm 0.96^{* \mathrm{xx}}$ \\
\hline & $\min$ & 0.010 & $0.010^{*}$ & $0.130^{*}$ & $0.020^{*}$ \\
\hline & $\max$ & 0.200 & $0.250^{* *}$ & $0.390^{* *}$ & $0.310^{*}$ \\
\hline \multirow{3}{*}{ summer kitchens } & $\mathrm{M} \pm \mathrm{m}$ & $0.094 \pm 0.48$ & $0.172 \pm 0.56^{*}$ & $0.239 \pm 0.72^{*}$ & $0.139 \pm 0.54^{* \alpha}$ \\
\hline & $\min$ & 0.010 & $0.009^{*}$ & $0.120^{* * *}$ & $0.010^{*}$ \\
\hline & $\max$ & 0.200 & $0.270^{*}$ & $0.370^{* *}$ & $0.290^{*}$ \\
\hline \multirow{3}{*}{ outdoors } & $\mathrm{M} \pm \mathrm{m}$ & $0.094 \pm 0.94$ & $0.164 \pm 1.06^{*}$ & $0.214 \pm 1.22^{*}$ & $0.120 \pm 1.20^{* \mathrm{x}}$ \\
\hline & $\min$ & 0.030 & $0.060^{*}$ & $0.030^{* * * *}$ & $0.007^{* *}$ \\
\hline & $\max$ & 0.210 & $0.320^{* *}$ & $0.400^{*}$ & $0.280^{*}$ \\
\hline
\end{tabular}

Note: $T_{1}$ - before cooking; $T_{2}-$ an hour after starting cooking; $T_{3}-$ at the end of cooking; $T_{4}-$ an hour after the end of cooking . " $p<0.001 .{ }^{* *} p<0.01 .{ }^{* * *} p<0.05$. (for $\left.T_{2}-T_{1} ; T_{3}-T_{1} ; T_{4}-T_{1}\right){ }^{a} p<0.001$. ${ }^{\text {ax }} p<0.01$. ${ }^{\text {axa }} p<005$. (for $\left.T_{4}-T_{3}\right)$

To sum up, the concentration of carbon monoxide was detected in few cases (values exceeding normal limits were recorded in 5 households), especially when preparing food in rooms designed for living and summer kitchen, when the fuel source was composed of biomass and residues of cereal crops. On the other hand, if the evaluation had been realized during the winter, there would have been probably many more results with high concentrations of carbon monoxide.

\section{Conclusions}

One of the most striking aspects of this problem is that only a reduced number of the population in Moldova has rooms exclusively for cooking, in other words corresponding to the hygienic norms. Added to that, much better conditions are confirmed in areas provided with natural gas pipelines, and with good ventilation systems.

Cooking in a living room (especially in winter) leads to supplementary pollution of the air in the living space; the situation is maintained by a traditional fuel-saving strategy: thermal preparation of the food is carried out, while at the same time economizing on space heating.

Moreover, the huge amount of people who cook in rooms that don't correspond to hygienic norms (with no ventilation or improper cooking installations) is at great risk of pneumonia, bronchitis, obstructive bronchitis, or even ischemic heart diseases. All the same, smoking is a supplementary factor that has to be taken into account. 
Finally, the current study was initiated because the Moldavian population does not have satisfactory conditions for food preparation, using fuel sources that are harmful to health, which are premises that damage children's health. The results of the research come with arguments and recommendations for the population, in order to decrease the bad impact on people's health.

Regarding all this data, we recommend increasing the level of information and education among the people of the Republic of Moldova by the means of efficient programs and community intervention projects, in order to raise public awareness of the exposure risks and to stimulate the adaptation of living conditions to a proper indoor environment.

Acknowledgment. The research reported in this publication was supported by the Fogarty International Center of the National Institutes of Health under Award Number R24TW009568. The content is solely the responsibility of the authors and does not necessarily represent the official views of the National Institutes of Health.

Conflict of interest. The authors of this article do not have any conflict of interests.

\section{Bibliography}

1. Almond, D., 2006. Is the 1918 Influenza Pandemic Over? Long-Term Effects of In Utero Influenza Exposure in the Post-1940 U. S. Population. Journal of Political Economy, 114(4), pp.672-712.

2. Alver, K., Meyer, H.E., Falch J.A. and Søgaard, A.J., 2010. Outdoor air pollution, bone density and self-reported forearm fracture. The Oslo Health Study. Osteoporosis Int, 21, pp.1751-1760. doi: $10.1007 / \mathrm{s} 00198-009-1130-8$

3. Banerjee, M., Siddique, S., Dutta, A., Mukherjee, B. and Ranjan, R.M., 2012. Cooking with biomass increases the risk of depression in pre-menopausal women in India. Soc Sci Med, 75(3), pp.565-72. doi: 10.1016/j.socscimed.2012.03.021.

4. Barnes, B.R., 2005. Interventions to reduce child indoor air pollution exposure in developing countries: behavioural opportunities and research needs. Children, Youths and the Environment, 15, pp.67-82.

5. Bruce, N., Perez-Padilla, R. and Albalak, R., 2000. Indoor air pollution in developing countries: a major environmental and public health challenge. Bulletin of the World Health Organization, 78, pp.1078-92.

6. Bruce, N.L., Rehfuess, E., Mehta, S., Hutton, G. and Smith, K., 2006. Indoor Air Pollution. In: D.T., Jamison, et al. Disease Control Priorities in Developing Countries, 2nd Edition, Washington. World Bank, New York: Oxford University Press.

7. Dutta, A., Mukherjee, B., Das, D., Banerjee, A. and Ray, M.R., 2011. Hypertension with elevated levels of oxidized low-density lipoprotein and anticardiolipin antibody in the circulation of premenopausal Indian women chronically exposed to biomass smoke during cooking. Indoor Air, 21(2), pp.165-76. doi: 10.1111/j.1600-0668.2010.00694.x.

8. Saha, H., Mukherjee, B., Bindhani, B. and Ray, M.R., 2015. Changes in RANKL and osteoprotegerin expression after chronic exposure to indoor air pollution as a result ofcooking with biomass fuel. J Appl Toxicol, doi: 10.1002/jat.3275.

9. Schneider, T., 2008. Resolving indoor air problems. SJWEH Suppl, 4, pp. 25-29.

10. Smith, K.R., Samet, J.M., Romieu, I. and Bruce, N., 2000. Indoor air pollution in developing countries and acute lower respiratory infection in children. Thorax, 55, pp.518-532.

11. ***World Health Organization. Household air pollution and health. Fact sheet $\mathrm{N}^{\circ} 292$. Available at: 〈http://www.who.int/mediacentre/factsheets/fs292/en/> [Accessed 12 august 2015]. 